\begin{tabular}{|c|c|c|c|c|c|c|c|}
\hline \multirow[t]{2}{*}{$\begin{array}{l}\text { Disease } \\
\text { activity }\end{array}$} & \multicolumn{4}{|l|}{ BASDAI } & \multicolumn{3}{|l|}{$\begin{array}{l}\text { ASDAS } \\
- \text { CRP }\end{array}$} \\
\hline & $\begin{array}{c}\text { month of } \\
\text { conception }\end{array}$ & trimester & imester & rimester 3 & trimester 1 & trimester & $\begin{array}{c}2 \text { trimes- } \\
\text { ter } 3\end{array}$ \\
\hline inactive/low & $57,8 \%$ & $33,3 \%$ & $25,7 \%$ & $35,3 \%$ & $16,7 \%$ & $14,3 \%$ & $14,7 \%$ \\
\hline mild & $30,6 \%$ & $36,1 \%$ & $40 \%$ & $26,5 \%$ & $42,2 \%$ & $28,6 \%$ & $32,4 \%$ \\
\hline high & $11,1 \%$ & $30,6 \%$ & $31,4 \%$ & $31,4 \%$ & $33,3 \%$ & $48,6 \%$ & $41,2 \%$ \\
\hline very high & $5,6 \%$ & 0 & $2,9 \%$ & $2,9 \%$ & $2,8 \%$ & $8,9 \%$ & $11,8 \%$ \\
\hline
\end{tabular}

When dividing patients into two groups depending on AS activity in the I trimester (group 1-low activity, group 2-moderate, high and very high activity), no significant change in the values of both BASDAI and ASDAS - CRP was identified in each group during pregnancy.

Conclusion: A tendency of increasing AS activity during the first half of pregnancy with no reverse until the end of gestation based on BASDAI and ASDAS - CRP values and CRP levels was found. There was a discrepancy in degree of activity assessed by the tools used: moderate and high disease activity was identified in greater number of AS patients based on ASDAS-CRP scores compared to BASDAI during the entire pregnancy. It is deemed necessary to continue research so that to identify the most adequate index for AS activity assessment during pregnancy.

Disclosure of Interests: Olga Krichevskaya: None declared, Zuleykhan Gandaloeva: None declared, Tatiana Dubinina Speakers bureau: Novartis, BIOCAD, MSD, Pfaizer, Abbvie, UCB, Anastasiya Demina: None declared DOI: 10.1136/annrheumdis-2020-eular.3959

\section{SAT0378 THE RELATIVE DIAGNOSTIC UTILITY OF INFLAMMATORY BACK PAIN CRITERIA IN AN INCEPTION COHORT OF PATIENTS WITH PSORIASIS, IRITIS, AND COLITIS PRESENTING WITH UNDIAGNOSED BACK PAIN}

G. Kröber ${ }^{1}$, U. Weber ${ }^{1}$, R. Carmona ${ }^{2}$, J. Yeung ${ }^{3}$, J. Chan ${ }^{4}$, S. Aydin ${ }^{5}$, L. Martin ${ }^{6}$, A. Masetto ${ }^{7}$, S. Keeling ${ }^{8}$, O. Ziouzina ${ }^{6}$, S. Rohekar ${ }^{9}$, R. Dadashova ${ }^{10}$, J. Paschke ${ }^{10}$ A. Carapellucci ${ }^{10}$, R. G. Lambert ${ }^{8}$, W. P. Maksymowych ${ }^{8,10} \cdot{ }^{1}$ University of Southern Denmark, Sønderborg, Denmark; ${ }^{2}$ St. Joseph's Healthcare Hamilton, Hamilton, Canada; ${ }^{3}$ James Yeung Rheumatology, Richmond, Canada; ${ }^{4}$ Artus Health Centre, Vancouver, Canada; ${ }^{5}$ The Ottawa Hospital, Ottawa, Canada; ${ }^{6}$ University of Calgary, Calgary, Canada; ${ }^{7}$ Université de Sherbrooke, Sherbrooke, Canada; ${ }^{8}$ University of Alberta, Edmonton, Canada; ${ }^{9}$ Lawson Health Research Institute, London, Canada; ${ }^{10} \mathrm{CARE}$ Arthritis, Edmonton, Canada

Background: Clinicians rely on the elicitation of features of inflammatory back pain (IBP) for diagnosis of axial spondyloarthritis $(\operatorname{axSpA})$ but the utility of IBP criteria in patients presenting with extra-articular features of axSpA remains unclear. Assessment of utility should include not only rheumatologist diagnosis as benchmark but imaging to address the circularity between elicitation of IBP and clinical diagnosis.

Objectives: To assess the diagnostic utility of all criteria for IBP in patients with psoriasis, iritis, or colitis and undiagnosed back pain using the rheumatologist diagnosis and imaging as benchmarks.

Methods: Consecutive patients $(n=246)$ with undiagnosed back pain $\leq 45$ years of age, $\geq 3$ months, with any one of psoriasis $(n=46)$, acute anterior uveitis (AAU)

Table 1. Rheumatologist diagnosis as external reference.

\begin{tabular}{lllll}
\hline & Sensitivity & Specificity & LR+ & LR- \\
\hline Psoriasis & & & & \\
ASAS IBP & $65.00 \%$ & $52.00 \%$ & 1.35 & 0.67 \\
Berlin IBP & $80.00 \%$ & $36.00 \%$ & 1.25 & 0.56 \\
Calin IBP & $80.00 \%$ & $28.00 \%$ & 1.11 & 0.71 \\
All 3 criteria sets & $60.00 \%$ & $56.00 \%$ & 1.36 & 0.71 \\
IBP global $>5$ & $85.00 \%$ & $36.00 \%$ & 1.33 & 0.42 \\
AAU & & & & \\
ASAS IBP & $84.44 \%$ & $42.86 \%$ & 1.48 & 0.36 \\
Berlin IBP & $80.00 \%$ & $57.14 \%$ & 1.87 & 0.35 \\
Calin IBP & $93.33 \%$ & $17.86 \%$ & 1.14 & 0.37 \\
All 3 criteria sets & $77.78 \%$ & $60.71 \%$ & 1.98 & 0.37 \\
IBP global $>5$ & $86.67 \%$ & $57.14 \%$ & 2.02 & 0.23 \\
IBD & & & & \\
ASAS IBP & $78.43 \%$ & $45.07 \%$ & 1.43 & 0.48 \\
Berlin IBP & $82.35 \%$ & $52.11 \%$ & 1.72 & 0.34 \\
Calin IBP & $84.31 \%$ & $19.72 \%$ & 1.05 & 0.80 \\
All 3 criteria sets & $70.59 \%$ & $57.75 \%$ & 1.67 & 0.51 \\
IBP global $>5$ & $80.39 \%$ & $66.20 \%$ & 2.38 & 0.30 \\
\hline
\end{tabular}

( $n=73)$, or colitis $(n=127)$ had diagnostic evaluation by a rheumatologist. Majority central reader assessment of MRI indicative of axSpA and diagnosis by the rheumatologist were external standards for testing the utility of these IBP criteria: ASAS, Berlin, Calin, rheumatologist global for IBP $>5$ (0-10 scale).

Results: AxSpA was diagnosed in $44.4 \%, 61.6 \%$, and $41.8 \%$ of patients with psoriasis, iritis, and IBD, respectively. Diagnostic utility for all IBP criteria was comparably poor (Table 1). MRI was indicative of axSpA in $21.2 \%, 43.5 \%$, and $19.7 \%$ of patients with psoriasis, iritis, and IBD. The utility of the IBP criteria was even worse using MRI as the external reference (Table 2), especially in patients with psoriasis. Only $14 \%$ of psoriasis patients with a positive MR reported "improvement with exercise but not rest" as compared to $70 \%$ and $62 \%$ of patients with iritis and IBD, respectively.

Table 2. Central assessment that MRI is indicative of axSpA as external reference.

\begin{tabular}{lcccc}
\hline & Sensitivity & Specificity & LR+ & LR- \\
\hline Psoriasis & & & & \\
ASAS IBP & $28.57 \%$ & $38.46 \%$ & 0.46 & 1.86 \\
Berlin IBP & $42.86 \%$ & $15.38 \%$ & 0.51 & 3.71 \\
Calin IBP & $71.43 \%$ & $23.08 \%$ & 0.93 & 1.24 \\
All 3 criteria sets & $14.29 \%$ & $42.31 \%$ & 0.25 & 2.03 \\
IBP global >5 & $85.71 \%$ & $23.08 \%$ & 1.11 & 0.62 \\
AAU & & & & \\
ASAS IBP & $75.00 \%$ & $26.92 \%$ & 1.03 & 0.93 \\
Berlin IBP & $70.00 \%$ & $38.46 \%$ & 1.14 & 0.78 \\
Calin IBP & $90.00 \%$ & $15.38 \%$ & 1.06 & 0.65 \\
All 3 criteria sets & $65.00 \%$ & $38.46 \%$ & 1.06 & 0.91 \\
IBP global >5 & $75.00 \%$ & $38.46 \%$ & 1.22 & 0.65 \\
IBD & & & & \\
ASAS IBP & $92.31 \%$ & $37.74 \%$ & 1.48 & 0.20 \\
Berlin IBP & $76.92 \%$ & $39.62 \%$ & 1.27 & 0.58 \\
Calin IBP & $92.31 \%$ & $16.98 \%$ & 1.11 & 0.45 \\
All 3 criteria sets & $76.92 \%$ & $45.28 \%$ & 1.41 & 0.51 \\
IBP global >5 & $92.31 \%$ & $47.17 \%$ & 1.75 & 0.16 \\
\hline
\end{tabular}

Conclusion: All IBP criteria have poor diagnostic utility for diagnosis of axSpA, especially in patients with psoriasis. This reinforces the desirability of less subjective assessment tools, especially imaging.

Disclosure of Interests: Georg Kröber: None declared, Ulrich Weber: None declared, Raj Carmona: None declared, James Yeung: None declared, Jon Chan: None declared, Sibel Aydin: None declared, Liam Martin: None declared, Ariel Masetto: None declared, Stephanie Keeling: None declared, Olga Ziouzina: None declared, Sherry Rohekar: None declared, Rana Dadashova: None declared, Joel Paschke: None declared, Amanda Carapellucci: None declared, Robert G Lambert: None declared, Walter P. Maksymowych Grant/research support from: AbbVie, Novartis, Pfizer, and UCB, Consultant of: AbbVie, Boehringe Ingelheim, Celgene, Eli Lilly, Galapagos, Janssen, Novartis, Pfizer, and UCB Employee of: Chief Medical Officer of CARE Arthritis Limited, Speakers bureau: AbbVie, Janssen, Novartis, Pfizer, and UCB DOI: 10.1136/annrheumdis-2020-eular.5910

\section{SAT0379 C-REACTIVE PROTEIN TO ALBUMIN RATIO IS ASSOCIATED WITH DISEASE ACTIVITY IN PATIENTS WITH AXIAL SPONDYLOARTHRITIS}

Z. Zhong ${ }^{1,2}$, Y. Huang ${ }^{1}$, Q. Huang ${ }^{1}$, T. LI ${ }^{1}{ }^{1,2} .{ }^{1}$ Guangdong Second Provincial General Hospital, Department of Rheumatology and Immunology, Guangzhou, China; ${ }^{2}$ Southern Medical University, The Second School of Clinical Medicine, Guangzhou, China

Background: C-reactive protein to albumin ratio (CAR) has emerged as a significant biomarker to evaluate and predict systemic inflammation[1]. However, the role of CAR in patients with axial spondyloarthritis (axSpA) remains unknown.

Objectives: The aim of this study was to investigate the relationship between CAR and disease activity of axSpA.

Methods: A total of 241 patients and 61 healthy controls from Guangdong Second Provincial General Hospital from December 2015 to August 2019 were retrospectively recruited in this study. Patients were divided into two groups, with 176 patients in remission group (BASDAl<4) and 65 patients in active group (BASDAl $\geq 4)$. Erythrocyte sedimentation rate (ESR), C-reactive protein (CRP), albumin (ALB), CAR, neutrophil-lymphocyte ratio (NLR), platelet-lymphocyte ratio (PLR) and monocyte-lymphocyte ratio (MLR) were detected. The correlations between CAR, NLR, PLR, MLR and disease activity were analyzed by the Spearman's correlations analysis. Receiver 